\title{
PARTICIPATORY RURAL DEVELOPMENT PROGRAM AND LOCAL CULTURE: A CASE STUDY OF MARDAN, PAKISTAN
}

\author{
I.A. $\mathrm{SHAH}^{1} \&$ N. BAPORIKAR ${ }^{2}$ \\ ${ }^{1}$ COMSATS Institute of Information Technology, Abbottabad, Pakistan. \\ ${ }^{2}$ COAS Salalah, Ministry of Higher Education, Sultanate of Oman.
}

\begin{abstract}
Research on rural development has gained significance in recent years. Much of the previous work focused on economic factors of the people involved in rural development programs/projects. However, now there is a growing interest in the role of socio-cultural factors affecting rural development. This paper reviews and analyzes how a German assisted Integrated Rural Development Program (IRDP) effectively and efficiently incorporated the people of a diverse culture of Mardan Division of North West Frontier Province, Pakistan in the development activities through a process oriented socio-cultural approach. The new way of viable participatory institution building at meso level (Regional Development Organizations) to tie and pursue the interest of micro-level organizations (Community Based Organizations) based on traditional, cultural values, and norms indicates how participation can be effectively institutionalized and the continuity of collective actions is ensured in the shape of Integrated Rural Support Program even after the withdrawal of IRDP. Based on the interviews, discussions, observations, and references, it is evident that the IRDP participatory approach not only facilitates genuine participation of the people in problem solving, planning, institutional building, and implementation of development activities but also ensures the sustainability of grass root organizations in the long run.

Keywords: culture, Integrated Rural Development Project, people's participation, rural development, sustainability.
\end{abstract}

\section{INTRODUCTION}

The pivotal role of people's participation in development is re-emerging in economic and social thinking [1] and its notion is widely recognized as an operational principle of development programs and projects [2]. It is one of the most important approaches for realizing self-reliant, sustainable development and social justice [3,4]. While the approach of 'participatory development' is generally well accepted, effective implementation of the approach remains a challenge [5] because many cultural, economical, and political barriers effectively prevent the poor from having any real stake in development activities [6]. Similarly, the development planners would rarely succeed when they impose their schemes on communities (or nations) without paying attention to the practices, customs, rules, laws, beliefs, values, and organizations of the people to be affected [7]. To enhance community mobilization, the development agencies' plans should be culture dynamics as diverse socio-economic standing and cultural backgrounds can slow down the process of mobilization [8]. Thus, for development institutions and planners, the challenge is how to incorporate a diverse culture, language, ecological adaptation, and history into development planning [9].

Promoting people's participation implies a very different way of working, different approaches and methods, and different expectations [2]. In this case study, the participatory approach of Integrated Rural Development Program (IRDP) ${ }^{1}$ in Mardan to incorporate local people belonging to the unique culture has been reviewed and analyzed. The approach is based on local culture, which effectively, efficiently, and purposively guided the promotion of participation during the project lifetime and ensured the sustainability of the project activities even after the support phasing out.

The above paragraphs in the paper outline the main issues due to focus on participation, and Section 2 points to constraints and potentials in the socio-cultural context of North West Frontier Province (NWFP), Pakistan. Section 3 in the paper gives a brief introduction of IRDP Mardan and in Section 4, the steps

(C) 2010 WIT Press, www.witpress.com

ISSN: 1743-7601 (paper format), ISSN: 1743-761X (online), http://journals.witpress.com DOI: $10.2495 / \mathrm{SDP}-\mathrm{V} 5-\mathrm{N} 1-31-42$ 
taken by IRDP Mardan to foster participation through the establishment of appropriate intuitional framework at micro, meso, and macro levels are provided. Impact of the participatory approach on community has been described in Section 5, by field visits, discussions, and analyzing the project documents. The last section looks at possibilities for further sustainability of project activities and community empowerment, keeping in view the limitations of IRDP Mardan. The overall goal is to identify lessons which may be useful in designing future participatory rural development projects/programs.

\section{CONSTRAINTS AND POTENTIAL OF LOCAL SOCIO-CULTURAL VALUES}

Community participation and mobilization is a complex process as it relates to various norms and values, including, socio-cultural, economic, and ethnic community behavior. Analysis of two participatory poverty alleviation projects in NWFP Pakistan (i.e. SRSP ${ }^{2}$ district Charsadda and IRDP district Mardan) $)^{3}$ and the prevailing socio-cultural environment in the NWFP indicated that local and social culture is a constraint and create hurdles for participatory development projects and programs. However, these projects and programs have great potential and ensure sustainability if effectively incorporated in participatory projects [10]. SRSP has replicated a participatory model from the Aga Khan Rural Support Program (AKRSP) ${ }^{4}$ in Charsadda district, which is based on economic factors but ignored the socio-cultural, local custom, tradition, and ethnic aspects [11, 12]. Hence, local communities suspected SRSP of religious motivation [13]. This had resulted in public protests many times and demands to government to close down SRSP [14]. Project staff received threats from local people resulting in suspension of field activities several times. SRSP staff themselves believed that the root of the crisis was the socio-cultural character of the area [15]. A study conducted by Shah et al. [16] also found out that most problems faced by SRSP in Charsadda are cultural and religious suspicions. On the other hand, IRDP Mardan approach called the "new approach' (discussed in Section 4) is based on the traditional cultural values and norms, prevalent social structures, traditional institutions, and communication concepts [17]. This resulted in creating an organized form of institution which can exist and work effectively without any socio-cultural hurdle even after phasing out of IRDP Mardan [14].

Thus, prevailing socio-cultural values were the main constraints which created hurdles for SRSP. On the other hand, IRDP used the same factors to accelerate people's participation. Therefore, the basic aim of a participatory community development project/program should be to empower the poor and disadvantaged people of the community toward self-reliance and self-help through mechanisms without disturbing the prevailing socio-cultural norms and values of the community.

\subsection{Background}

\section{INTEGRATED RURAL DEVELOPMENT PROJECT MARDAN}

The Federal Republic of Germany assisted IRDP was launched in 1984 with the objective to promote 'the self help potential of the needier sections of the population', 'develop the infrastructure', 'improve health conditions', and 'contribute towards a long term increase of incomes' as well as the creation of new sources of income in the agricultural and non-agriculture sectors in collaboration and cooperation of the Local Government, Election and Rural Development Department of NWFP, Pakistan. The project was implemented in the rain-fed areas of Mardan Division, NWFP, Pakistan. The project consisting of five phases was completed on December 31, 2000.

To begin with, it was just a conventional rural development project and not really any different from any other such project. However, later, community elites were involved in the execution of development activities in an attempt for participation and this helped in gaining substantial experience in working with the rural people. 
The first two phases (1984-1987 and 1987-1990) were orientation and implementation with a narrow concept of participation through project committees, which often led to unjustified elite representation and domination. The project later on replaced the narrow concept of participation by the 'Village Organization' (VO) model taken from AKRSP, working successfully in the northern areas of Pakistan. However, no consideration was given to the complex socio-cultural milieu of the project area. As a result, it failed in accelerating the pace of social mobility and generating a dynamic process of change. This 'conceptual impotency' was acknowledged and the need was felt to reorient the project in consonance with the prevailing socio-cultural environment in order to achieve the ultimate aim. Accordingly, research was undertaken and a socio-cultural field survey was carried out, target groups analysis was done, relevant literature on Puktoon' ${ }^{5}$ history, culture, beliefs, and concepts were studied. This gave the project new impetus and it started with a renewed zeal when a new approach was adopted in 19921993. This new approach, later came to be commonly known as 'The New Approach'. The new approach was successfully implemented from 1993 onwards. The new approach was the target group's own approach as it matches the socio-cultural fabric of the target groups and included a special focus on the 'poorest of poor' (ethnic minorities) from the interior mountain areas of IRDP Mardan [12, 18, 19].

\subsection{Project area and people}

The IRDP Mardan extends over an area of $800 \mathrm{~km}^{2}$ approximately covering 13 union councils of the relatively underdeveloped northern parts of the districts Mardan and Swabi of Mardan Division, NWFP.

The total population of the project area is 217,729 (1996) and growing at a high rate of more than $3 \%$. The inhabitants of the area are tribes, where traditional culture values and norms (Pukhtoonwali) ${ }^{6}$ of the Pukhtoons, social structures (Khel, cham), ${ }^{7}$ traditional institutions (Jarga, Loya Jarga) ${ }^{8}$ and communication concepts (Hujra) ${ }^{9}$ are still traditionally unchanged and of high importance. Specific are also the norms and values, including 'purdah' ${ }^{10}$ applied for women, resulting often in extremely low levels of participation from women in public affairs and socio-economic activities. The major tribes/sub-tribes living in the project area are: the Mandanr and Yousufzai, ${ }^{11}$ the Uthmankhel, ${ }^{12}$ the Miangan, ${ }^{13}$ and the Gujar and $\operatorname{Ajar}^{14}[19,20]$.

\section{PARTICIPATORY INSTITUTIONAL DEVELOPMENT MODEL OF IRDP (NEW APPROACH)}

\subsection{Key elements}

The traditional culture, values, and norms (e.g. nang, tura, badal, imandari, rorwali, melmastia), ${ }^{15}$ prevailing social structures (Khel/cham), traditional institutions (Jarga, Loya Jarga), and communication concepts (Hujra) were the key elements of the 'new approach'.

\subsection{Conceptual components}

The conceptual components are:

- Establishment of four correlating and interdependent institutional village based organization (VBO) levels:

- Level 1: Village Organizations: The VOs were predominantly established at Khel and cham levels. The religious leaders (Pesh-e-Imam, Maulanas, Aalems) were encouraged to join the VOs as members, thus, reinforcing social cohesion. 
- Level 2: Umbrella bodies: The umbrella bodies consist of traditional institutions (village Jarga, Loya Jargas), semi traditional bodies (Gujar/Ajar Village Federation), and modern forms (Village Business Association), depending on the size of the village. Traditionally, the Jargas used to function primarily as social control regulatory mechanisms. The aim is to enlarge their function toward development orientation.

- Level 3: Community based non-governmental organizations (NGOs): It is emphasized that these local organizations cannot and should not be compared to the majority of the 'so-called' NGOs available elsewhere in Pakistan. These local NGOs are service-oriented toward VOs in their area of operation. They have emerged out of existing local organizational and institutional structures and are registered with the Social Welfare Department Government of NWFP, Pakistan. During the institutional process, the umbrella bodies (level 2) and local NGOs (level 3) mentioned above were merged and developed into Regional Development Organizations (RDOs). ${ }^{16}$ Presently, seven RDOs are working in Mardan (five RDOs) and Swabi (two RDOs) districts.

- Level 4: Regional Council for Development (RCD): The RCD consists of elected representatives of the seven RDOs (SESWA, SABA, SWOG, JATAN, IMFED, LOJA, and UFAQ). ${ }^{17}$ The cabinet of RCD consists of seven members (one from each NGO). The general body consists of 91 members, that is, 12 from each NGO. Seven seats were reserved for women, that is, one each from each NGO. RCD is now called Integrated Rural Support Program (IRSP). ${ }^{18}$

The resultant structure of IRDP Mardan is given in the Fig. 1.

- Creation of genuine group capital in the form of VBO self-administered village development funds

- Socially homogenous VO on Khel, cham, or ethnic basis

- Religious leaders as VO members/staff is another cohesive factor for the organizations and for the promotion of women oriented activities

- Recognition of Puktoon Jargas as working partners

- Establishment of VO federations, business coalitions, and associations

Macro Level

Restructure the Political Economy

Reform of Public services and

Public Policies

Reform the International Order

Meso Level

Regional Council for Development

*Integrated Rural Support Programme

Micro Level

\begin{tabular}{|l|l|}
\hline $\begin{array}{l}\text { Donor Agencies } \\
\text { InternationalNGOs } \\
\text { Departments }\end{array}$ \\
\hline \multicolumn{2}{|c|}{ National NGOs } \\
\hline $\begin{array}{c}\text { RCD* (Presently called IRSP*) having the following } \\
\text { Regional Development Organizations (RDOs): } \\
\text { (SESWA SABA UFAQ IMFED JATAN SWOG LOJA) }\end{array}$ \\
\hline \multicolumn{2}{|c|}{ Village Organizations (Men and Women) } \\
\hline
\end{tabular}

Figure 1: Resultant structure of the IRDP Mardan. 
- Introduction of IRDP and NGO Hujra days

- Amalgamation of traditional with appropriate modern organization elements

- Orientation towards socio-economic disadvantaged ethnic minorities in the interior mountain areas such as Gujar and Ajar

- Establishment of multiple linkages between the various organizations and external agencies such as donor agencies, ministries/departments: district, provincial, federal administration, Member Provincial Assembly, Member National Assembly and Senators [12, 18, 21, 22].

\subsection{Ways of people's participation}

IRDP Mardan has developed various ways to involve local people in developmental activities at grass root level with the objective of empowering them and sustaining their participation. People's participation adopted in the project is genuine, interactive, through partnership, self-mobilization, and self-management participation, which is considered the ideal and stronger types of participation in literature on 'people's participation'. As a first step, IRDP assisted people in the formation of an organized group called VO. In each village, VOs separate for men and women were developed in which all categories of local people were involved. All VOs affiliated to IRDP fulfilling the terms of partnership (ToP) were eligible for technical and financial support. The identification of a scheme was the responsibility of VO. After selection of a scheme, VO approached IRDP for technical and financial assistance through a written resolution. IRDP carries out different surveys and tests, and based on the analysis, a feasibility report was prepared. Self-help contribution in the scheme was also compulsory for VOs. Usually, self-help consisted of unskilled labor, local material such as sand and gravel, watch, ward, store facilities, and provision of land in case of roads and buildings. In most schemes, self-help varied from 5 to $7 \%$ of the scheme cost. Schemes found feasible (technically, socially, ecologically, and economically) were approved. After approval, VO was asked to have specific ToP for the scheme and this was a legal document. The scheme was then implemented through the VO, by funding them in installments. After the completion of scheme, a completion certificate was issued signed by IRDP official and VO. The scheme then was handed over to VO and the subsequent management, operation, and maintenance of the schemes then became the responsibility of the implementing VO.

Local people were involved in the whole process of development, i.e. from scheme's identification, till the completion of scheme. Sense of ownership of the schemes was introduced among the village people, by involving them during the whole process of development. Similarly, this sense of ownership was strengthened by the self-help contribution of the target groups. In most of the schemes such as irrigation, drinking water, and income generating, funds were generated from the schemes for future maintenance and operation [18, 19, 23].

\subsection{Salient features}

Participatory development models adopted in NWFP by various development agencies, including government and NGOs (e.g. AKRSP, SRSP, SUNGI, etc.), concentrate on micro-level organizations (community based organizations; CBOs). They are working directly with the grass-root communities at the micro-level, hoping that they will get linked to the local government, line departments and donors at the macro-level. However, this approach never empowers the target communities and is unsustainable because it is quite a normal feature that - as soon as one of the 'participatory' projects gets completed - the respective local organizations disappear. Moreover, the sustainability of these 
grass-root organizations after the phasing out of the project is overlooked and no consideration is given to their viability. In fact, the problem is that many community development programs ignore the very important area of developing meso-level institutions. There is no concrete strategy for linking micro-level organization (CBOs) and macro-level institutions (donor organizations, national and international NGOs, and government departments/ministries) with the help of meso-level organizations called RDOs [14]. The Food and Agriculture Organization also pointed out that CBO (small group approach) is only one element and is a 'building block' in a broader social capital strengthening process. Other broader and deeper forms of social capital also should be established. Once CBOs are stable and operational, they are encouraged to link together in inter-group associations. These secondary level organizations help small groups obtain larger economies of scale, tackle bigger community problems, strengthen negotiation power of the poor, and help in more efficiently building inter-group solidarity, developing links between the 'bottom' and the 'top'. These associations also often help to defend members groups against the excesses of local elites misusing their economic and political power in groups to neutralize governance reforms and emerging as locally growing power structures [1].

To tie up CBOs, sustain their activities, and link them with donors and other macro level national and international agencies, IRDP Mardan introduced meso-level organizations.

IRDP model is also different because it is process oriented, flexible, and incorporated local sociocultural aspects. On the other hand, all other models adopted in NWFP, Pakistan are blueprints replicated from AKRSP.

\section{IMPACT OF IRDP MARDAN PARTICIPATORY APPROACH}

The IRDP approach was tested on ground by carrying out field survey. Project staff, community, CBOs, and NGOs staff/members were consulted. Their views regarding project approach were quantified and are given in Table 1.

The analysis of data in the table and field observation indicated that the induction of sociocultural aspects and formation of meso-level organizations in IRDP model worked effectively and efficiently. It was find out that that the majority of the people who participated in project activities belonged to all classes and their response toward project was very positive because all project activities were in the framework of prevailing socio-cultural environment. Similarly, the analysis showed that the project empowered local people and ensured sustainability of its various activities even after phasing out of the project. All the RDOs still exist and are properly working in the

Table 1: Impact of IRDP approach on community.

\begin{tabular}{lcc}
\hline Activities & Impact on community & Respondent \\
\hline Self-help and self responsibility & Increased & $78.2 \%$ \\
Sustainability of project activities & Sustained & $75.2 \%$ \\
Community satisfaction & Satisfied & $97.1 \%$ \\
Achievement of project objective & Achieved & $92.2 \%$ \\
Awareness and confidence & Increased & $91.7 \%$ \\
People's empowerment & Empowered & $91.7 \%$ \\
Strengthening of disadvantage people & Increased & $95.6 \%$ \\
Managerial and financial capacity building & Not developed & $71.0 \%$ \\
\hline
\end{tabular}


supervision of IRSP. However, it was find out that their managerial and financial capacity has not been built up substantially and as a result they still depend on IRSP for funding as well as to pursue their activities with external agencies.

\section{POSSIBILITY FOR FURTHER SUSTAINABILITY AND EMPOWERMENT}

People's participation in development activities does not mean simply sharing costs and receiving benefits [24]. In participatory development projects, development is perceived as a way to empower people and improve their ability to control their lives, use and manage resources [25] because there is a limit for how long the donor agencies would stay with communities to build their capacities, deliver specific packages, and micro-credit [14]. The analysis of project documents and field observation indicated that the IRDP model stresses more on institutional building and gives less attention to the capacity building of people and local organizations. Field observations showed that most of CBOs and RDOs depend more on IRSP for funding. The reason is that IRDP Mardan participatory model did not concentrate on capacity building of individual and local institutions. Moreover, financially, IRDP model seems not very sustainable as IRSP, which is the coordinating body of all RDOs, does not have enough local resources to cover project costs.

Therefore, for sustainable participatory rural development project in NWFP, a more comprehensive strategy needs to be developed. The main characteristics of the strategy should include the following.

\subsection{Institutional development and its sustainability}

A question arises for how long the outsiders would come to plan for the community. How long would a development program be able to keep them organized? We build its capacity, we deliver specific packages, and micro-credit, but for how long would the outsiders stay with the community to keep it going? How do we sustain any services and for how long these external NGOs have to be around for the same purpose? How the services can be sustainable if they are always from outside-donor initiated? Such services always come to an end and the systems are left alone. How do we get sustainable system the people can rely on even when the donor funding is ended [14]? Thus, a sustainable institutional network is necessary to be developed by project from day one in order to continue the activities of donor projects after withdrawal of its resources because an organized community can gain the voice and strength to attain collective goal. The institutional network should be composed of CBOs (micro-level institutions) and local NGOs (meso-level institutions).

The formation of micro-level institutions (CBOs) and to tie them with meso-level institutions (RDOs) to sustain, strengthen, and unite them as well as to effectively raise their voice to the government and donors is not enough. The question is how they can be sustained after phasing out external projects/programs.

Institutional sustainability depends on managerial and financial strengths. These strengths can be measured by the existence of sound internal administrative policies and operational guidelines on the one hand, and on the ability to attract and manage financial resources on the other [26].

- Management capacity building: Institutional survival is usually at stake because of lack of direction and proper knowledge about organizational management and the skills needed to set up clear and achievable programs. Various technical and non-technical trainings to strengthening the capacity of local organizations to respond to the needs of their communities in a participatory, democratic 
fashion are necessary for institutional sustainability. The United Nations Development Program indicated three types of capacity building efforts:

- Provide training to enhance the participatory skills of NGOs. These skills are related to the NGOs' effectiveness in terms of demand identification, reciprocity, and community organization.

- Provide training to enhance the ethnical and managerial skills of NGOs. This involves accounting, financial reporting, sector specific techniques, for example, in children's issues, disability, finance, etc., or logistical management. Training in these areas leads to building up professional capacity and increased management effectiveness.

- Organizational or 'strategic' development including financial management, fund raising, human resources development, long term programmatic planning, and institutional relations with other actors within and outside the NGO sector [26].

- Financial capacity building: As mentioned above, institutional sustainability depends upon financial sustainability. Various institutions (CBOs and NGOs) are financially unsustainable after phasing out donor development projects and programs. Therefore, such schemes/activities should be included in the projects/programs from day one which can financially sustain all the CBOs/ NGOs during and after withdrawal of development project/program. More stress is needed on income-generating activities such as producing products based on appropriate technology for local and export markets. These products are to be made by rural communities with credit, technology, and marketing assistance from the project/program. In addition, there need to be fund-raising activities to enhance funding from community sources. Other local available resource can be used to enhance $\mathrm{CBO}$ /NGOs funds for their present and long run sustainability.

- Thus, focus on CBOs/NGOs management capacity building and financial capacity building is necessary from day one of a rural development project/program.

\subsection{Socio-cultural sustainability}

For sustainable activities/programs, the participatory model should be based on local culture. For example, after 50 years of development efforts in India, particularly in the rural areas, many evaluation reports of development programs and projects observe a differential response of target groups to the interventions. Apart from a few success stories, many projects lack social sustainability. Once the change agents leave the field, the target groups gradually fall back on earlier practices [27].

\subsection{Exit strategy/phasing out of project/program}

Many development projects/programs failed to achieve sustainability in the long run because they have no proper strategy to exit/phase out [14]. In the existing literature, no mechanism is available to practically verify the existence of CBOs or to monitor their development activities after project completion. Therefore, a strategy needs to be developed on how development will be maintained or how it will be continued by communities after withdrawal of the projects/ programs. Since the CBOs are the basic block of the whole rural development model, therefore, all the focus should be on their sustainability right from the beginning of the project/program. The ultimate objective of the projects/programs should be to build the capacity (management and financial) of CBOs to make them self-managing, self-financing, and self-reliant, multi-level institutions to the extent that the external program can phase out from the area at some suitable point in time. 


\section{CONCLUSION}

The IRDP Mardan concept and implementation is generally appreciated as a culturally sensitive and locally well-adjusted approach. IRDP has not only left behind hundred of VBOs but also an ideal network of grassroots organizations linked with umbrella or meso-level RDOs and RCD in the shape of IRSP.

The first major pillar of the IRDP Mardan is the 'new approach'. This approach is unique in its style of composition and operation at field level. The process of reaching to the poorest of the poorest and involving them in their own development is only possible through this approach in a complex socio-culture situation like the case of Mardan. The technique envisaged an agenda of multi-level institution building and empowerment of poor people by keeping in view their socio-culture values and norms. The process helped in enhancing self-confidence, creating the sense of ownership, reducing the cost of development operations and accelerating the pace of people's empowerment in the prevailing society of Mardan division. The elements of the 'new approach' within the context of traditional structure are much fitted to the modern development concepts of participation and selfhelp. The joint management of common resources, self-help and self-responsibility, and self-administration at Khel (street), village, and regional levels enhance sustainability and empowerment. The innovation of the project to link the created VOs with traditional institutions appears to contribute positively to the concept of participatory development.

Theoretically, IRDP model is more comprehensive, process oriented, focusing on institutional building and applicable in any socio-cultural setting. However, the model lacks capacity building of beneficiaries/CBOs/NGOs. The capacity should be built enough so that they can choose the terms of relationship with outsider agencies in order to continue the growth of their organization according to their needs and priorities in the later period.

\section{NOTES}

1. IRDP was a bilateral project financed by the Federal Republic of Germany through GTZ (Gesellschaft Technische Zusammenarbeit) and the Provincial Government of North West Frontier Province, Pakistan.

2. Sarhad Rural Support Program (SRSP) is a provincial level NGO established in the NWFP Pakistan in 1989 with the objective of alleviating rural poverty at the grassroots level through training and institutional building for sustainable development.

3. Charsadda and Mardan are the two adjoining districts of NWFP with the same culture and tradition.

4. AKRSP was initiated and guided by the international Aga Khan Foundation, an NGO of the Ismaelis (sub-clan of Muslim).

5. The majority of the population in NWFP traces their origin with Afghanistan and Central Asia and is called Pukhtoon. They speak Pukhto language and write with an Arabic script. They take pride in being Pukhtoon and are famous for their hospitality and generosity.

6. Pukhtunwali: Pukhtunwali means the Pukhtoon (Pathan/Pashtun) way of life. The simplest definition of Pukhtoonwali is 'The way of the Pathans'.

7. Khel/Cham: A Pukhtoon Khel is a particular decent group, thus, a clan according to sociological definition. Depending on the size, a village in the project area may consist of one to eight Khels. This Khel system constituted by consanguinity manifests a high degree of solidarity with reciprocal claim/demands, rights and obligations of all the clan families.

8. Jarga/Loya Jarga: The Jirga is a council of the leaders of various Pukhtoon tribes, who function as arbitrators. In Pakhtoon communities, Jarga play an important and constructive role in community life according to precise rules and protocols. It is an authority for settling disputes and dispensing even-handed justice to all irrespective of their social status, influence, and wealth. The Jirga plays both executive and judicial roles and settles all disputes pertaining to the distribution of land, prop- 
erty, blood feuds, blood money, and other important inter-tribal affairs on the basis of tribal conventions, traditions, and principles of justice. Loya Jarga: The Council of leaders at regional level.

9. Hujra: The Hujra, which represents the social character of the Pukhtoons, is an institution. It serves as a club, dormitory, guest house, and a place for ritual and feastings. It is a centre for social activities as well as a council hall for the settlement of family and inter-tribal disputes.

10. Purdah: Purdah is a tradition of keeping women hidden from the eyes of men who are not family members.

11. The Mandanr and Yousufzai are Pukhtoon. More than $60 \%$ of the population belong to this domination group, which owns individually (arable land but also to some extent rangeland) or as a group (mostly rangelands) most of the land resources in the area including in the mountains.

12. The Uthmankhel are also Pukhtoons (population share 11\%). They own arable land as well as rangeland and settle in one valley in the western part of the Katlang zone.

13. The Miangan (9\%) are of Arab origin (religious teachers) but have adapted to Pukhtoon values. They do not own land, but are allowed to cultivate arable land without paying land rent. They have no ownership right to rangelands.

14. The Gujar and Ajar (17\%) are an ethnic minority of non-Pukhtoon origin. They have adopted to a considerable extent the culture values of the Pukhtoons and have socio-economic interactions with them.

15. Nang: The Pukhtunwali system revolves around 'Nang' the code of honor. Every Pathan must maintain his 'Ghairet' (pride) and display his 'Tura' (bravery). A Pathan must avenge any insult against him, his family, and tribe. The ideal of a Pukhtoon (man and woman) is the person who unconditionally protects the weak, the family, the lineage, the clan, the tribe, and the Pukhtoon people. He/she sacrifices egoism in favor of altruism and is thus called 'nangialay'.

Tura: The notion 'tura' (sword) implies heroism, brevity and is the prestige of an individual.

Badal: 'Badal' (revenge) is the driving force of Pathan society. It is mostly seen as the obligation for blood feud. The actual meanings of badal are exchange, compensation, reciprocal assistance, and to arrive at a situation of balance.

Melmastia: A concept of 'Melmastia' (hospitality) of Pukhtoon culture is very famous. Pukhtoon have been described as one of the most hospitable peoples of the world. A Pukhtoon feels delighted to receive a guest regardless of his past relations or acquaintance and prepares a delicious meal for him.

Imandari: Honesty

Rorwali: Brotherhood

Malgartia: Friendship

Badraga: Armed escort for guests of honor

16. During institutional process, the umbrella bodies consisted of traditional institutions (Village Jarga and Loya Jarga), semi-traditional bodies (Gujar/Ajar village federation, i.e. Interior Mountain Federation), modern business association (Shaheen Welfare Organization Gundo) and local NGOs, which were merged and developed into seven RDOs.

17. SESWA: Shewa Educated Social Workers Association

SABA: Social Association Babuzia Abakhel

SWOG: Social Welfare Organization Ghundo

JATAN: Samaji Behbood Jarga Tanzeem Kohi Bermole

IMFED: Interior Mountain Village Organization Federation

LOJA: Loya Jarga of Lower Rustum

UFAQ: United Friends Association Qasmi 
18. RDOs which were continuously working with IRDP Mardan for social mobilization and supported local community based organizations, realized the need of a central coordinating, managing, and lobbying body that could replace IRDP after its phasing out. The RDOs thus jointly decided to form a divisional level body to maintain the pace of socio-economic development in the area with the local government, external donors and other development organizations. Thus, the RDOs joined hands to establish the Regional Council for Development called IRSP.

\section{REFERENCES}

[1] FAO, Participation in Practice: Lessons from the FAO People's Participation Programme, Food and Agriculture Organization: Rome, 1997.

[2] UNDP, UNDP Guidebook on Participation, United Nations Development Programme: Washington, DC, 1997.

[3] SURF, Participatory Development: Risks \& Conditions for Success, Sub-Regional Resources Facilities for Arab State (SURF-AS): Beirut, 1999.

[4] JACA, Participatory Development and Good Governance: Report of the Aid Study Committee, Japan International Cooperative Agency (JICA): Japan, 1995.

[5] UN, People's Participation for Community Development: Six Innovative Approaches Submitted for the 1996 ESCAP HRD Award, United Nations, Economic and Social Commission for Asia and the Pacific, New York, 1998.

[6] World Bank, The World Bank Source Book on Participation, World Bank: Washington, DC, 1996.

[7] Kottak \& Conrad, P., Participatory development: rhetoric and reality. Development Anthropology, 13(1-2), pp. 1, 3-8, 1995.

[8] Victoria, A. \& Bantista, Citizen empowerment through participation in the context of poverty alleviation. The Role of Public Administration in Alleviation Poverty and Improving Governess, ed. J. Jabes, Asian Development Bank, 2005.

[9] Davis Shelton, H. \& Soeftestad Lars, T., Participation and Indigenous People, Environment Department Dissemination Note Number 21, World Bank: Washington, DC, 1995.

[10] Shah, I.A., People's Participation in Rural Development Projects in the North-West Frontier Province of Pakistan: A Comparative Review and Analysis of Sarhad Rural Support Programme (SRSP) and Integrated Rural Development Project (IRDP), African and Asian Studies 8 (2009), pp. 175-184, 2009.

[11] Fischer, K.M. \& Khan, M.A., A Consultancy Report Prepared on Behalf of Deutsche Gesellschaft fur Technische Zusammenarbeit (GTZ) POYLENBERG, 1. November 1998.

[12] Abid, U.J., Cruising Through Turbulence: Pak-German IRDP Experiences in Integrated Rural Development Project, NWFP: Mardan, Pakistan, 2000.

[13] SRSC, A Mid Term Review, Sarhad Rural Support Corporation, NWFP: Pakistan, 1996.

[14] Abid, U.J., Development Meso-level Institutions: A Guide for Rural Development Practitioners, Policy Makers, Programmes and Donors, Integrated Rural Support Programme, NWFP: Pakistan, 2001.

[15] SRSC, End of Phase Evaluation, Sarhad Rural Support Corporation, NWFP: Pakistan, 1998.

[16] Shah, et al., Rural development; an assessment of participatory development approach in NWFP (a case study of attitude of people towards "SRSC" in District Charsadah). Research Journal, Gomal University D.I. Khan, Pakistan, 2007.

[17] Rehman, A., The Green Miracle of Jalal: Forest Trees and People, Newsletter issue 32/33, February 1997, Forestry and Planning Division, Forestry Department, FAO, Rome, Italy, 1997. 
[18] Czech, H.J. \& Zaman, G., Report on The Restructuring of RCD, Integrated Rural Development Project, Mardan, NWFP, Pakistan, 1999.

[19] Eschborn, G., Main Report: Project Progress Review of the Pak-German Integrated Rural Development Project, Mardan, NWFP, Pakistan, 1996.

[20] IRDP, Introduction to IRSP: The Grassroots Institutional Development by Pak-German IRDP Mardan from 1984-2000, Integrated Rural Support Programme (IRSP), Mardan, NWFP, Pakistan, Undated.

[21] Czech, H.J., The Group Capital Concept: A Concept Based on the Culture, Social Norms and Islamic Values of the Pukhtoons, Gujars and Ajars, Pak-German Integrated Rural Development Project, Mardan, NWFP, Pakistan, 1994.

[22] Czech, H.J., The New Approach: A Possible Participatory Development, Integrated Rural Development Project, Mardan, NWFP, Pakistan, 1996.

[23] Akbar, J., Report on Agriculture \& Agro-forestry, Pak-German Integrated Rural Development Project, Mardan, NWFP, Pakistan, 2000.

[24] Bruns, B., Promoting participation in irrigation: reflections on experience in Southeast Asia. World Development, 21(11), pp. 1837-1849, 1996. doi:10.1016/0305-750X(93)90086-O

[25] Wells, M., Brandon, K. \& Hornah, L., People and Park: Linking Protected Area Management with Local Communities, World Bank, World Wildlife Fund and USAID: Washington DC, 1992.

[26] UNDP, Capacity Assessment of the NGO Sector in Kyrgyzstan, UNDP, 2000-2002.

[27] University of Mysore, Conference Proceedings: International Seminar on Linguistic and Interdisciplinary Approaches as Critical Resources to Development, Audio-Visual Research Centre (AVRC), 2000. 